ISSN 2304-8158

www.mdpi.com/journal/foods

Article

\title{
Functional Starters for Functional Yogurt
}

\section{Mattia P. Arena ${ }^{1, \dagger}$, Graziano Caggianiello ${ }^{1, \dagger}$, Pasquale Russo ${ }^{1,2}$, Marzia Albenzio 1 , Salvatore Massa $^{1}$, Daniela Fiocco ${ }^{3}$, Vittorio Capozzi ${ }^{1,2}$ and Giuseppe Spano ${ }^{1, *}$}

1 Department of Agricultural, Food and Environmental Sciences, University of Foggia, Via Napoli 25, Foggia 71122, Italy; E-Mails: mattiapia.arena@unifg.it (M.P.A.); graziano.caggianiello@unifg.it (G.C.); pasquale.russo@unifg.it (P.R.); marzia.albenzio@unifg.it (M.A.); salvatore.massa@unifg.it (S.M.); vittorio.capozzi@gmail.com (V.C.)

2 Promis Biotech s.r.l., Via Napoli 25, Foggia 71122, Italy

3 Department of Clinical and Experimental Medicine, University of Foggia, Via Pinto 1, Foggia 71122, Italy; E-Mail: daniela.fiocco@unifg.it

$\dagger$ These authors contributed equally to this work.

* Author to whom correspondence should be addressed; E-Mail: giuseppe.spano@ unifg.it; Tel.: +39-0881-589-303.

Academic Editor: Christopher J. Smith

Received: 13 November 2014 / Accepted: 16 January 2015 / Published: 5 February 2015

\begin{abstract}
In this study, we investigated the multifunctionality (microbial starters and probiotics) of Lactobacillus plantarum WCFS1 and Lactobacillus plantarum CECT 8328 strains used as microbial starters for the production of yogurt in combination with Lactobacillus delbrueckii ssp. bulgaricus and Streptococcus thermophilus. The ability of the probiotic strains to survive oro-gastrointestinal stresses was monitored by an in vitro assay simulating the human digestive tract. The transcriptional level of several genes involved in the immune response suggested that the probiotic strains may have a favorable influence on immunomodulation. Overall, this study revealed that the tested Lactobacilli exhibited suitable technological features for yogurt production and might be used to formulate novel food with immunomodulating effects.
\end{abstract}

Keywords: yogurt; riboflavin; multifunctional strains; probiotic 


\section{Introduction}

Lactic acid bacteria (LAB) are traditionally used to obtain fermented food from different raw materials, e.g., milk, vegetable, cereal and meat products [1,2]. Moreover, several strains of LAB are able to confer health benefits to humans [3], presenting probiotics features, e.g., reinforcement of the intestinal epithelial barrier, reduction of allergies, antagonism against pathogens and modulation of gut-associated lymphoid tissue (GALT) immune activity [4-7]. The human gastrointestinal system fulfils the important role of digesting and absorbing the molecules ingested through the diet required for cell growth and activity. Therefore, it is the principal interface between human tissues and external factors, such as food and microorganisms [8]. The human gastrointestinal system acts also as a central component of the immune system, performing both the function of a physical barrier and producing different types of immune mediators, i.e., cytokines, which have the role of initiating, sustaining and modulating the immune response against injury, microbial attacks and other antagonistic stimuli $[9,10]$. However, immune homeostasis, that is the maintaining of a well-balanced ratio between pro- and anti-inflammatory processes $[11,12]$, can be compromised, in particular inflammatory gut diseases, such as Crohn's disease (CD) and ulcerative colitis (UC), in the case of stress conditions, in allergic diseases and due to aging factors [13-15]. Some diet components have been shown to modulate and/or maintain immune homeostasis [16]. Similarly, one of the most important actions on the gut immune system of probiotic bacteria is the ability to influence the genes coding for cytokines, affecting the function of various immune parameters by immuno-stimulation and/or immunomodulation action.

Haller et al. [17] demonstrated that a strain of Lactobacillus sakei was able to induce the transcriptional level of genes coding for pro-inflammatory cytokines, i.e., IL-1 $\beta$, IL-8 and apoptosis inducer TNF- $\alpha$. Likewise, Lactobacillus helveticus and Lactobacillus acidophilus have been shown to have the capability to enhance the production of cytokines IL-6 by intestinal epithelial cells $[4,18]$. Moreover, Grimoud et al. [19] demonstrated that the anti-inflammatory properties of several probiotic bacteria, including strains of Bifidobacterium bifidum, Lactobacillus acidophilus, Lactobacillus lactis and Lactobacillus plantarum, were able to reduce IL- 8 secretion in stimulated intestinal cells. Interestingly, it was also proven that Lactobacillus rhamnosus GG inoculated in milk significantly downregulated the gene expression of CR1, CR3, Fc $\gamma$ RIII and FC $\alpha$ R, important phagocytosis receptors that are highly expressed in milk-hypersensitive patients [20]. Ogawa et al. [21] showed a symbiotic influence of the probiotic bacteria, Lactobacillus casei ssp. casei, and dextran to enhance the efficiency of IL-15 production.

Consequently, behind a growing consumer demand for health-promoting and disease-preventing food, the investigation on microorganisms with both technological and probiotic characteristics has increased in recent years, aiming to develop novel products with higher physical, chemical, technological and functional quality.

The aim of this study was to investigate the potential immunomodulatory effects of Lactobacillus plantarum WCFS1 and Lactobacillus plantarum CECT 8328 strains inoculated into yogurt fermented with Lactobacillus delbrueckii ssp. bulgaricus and Streptococcus thermophilus. Differences in terms of $\mathrm{pH}$, the content of lactic acid, fat, proteins, casein, nitrogen fractions and peptide profiles were evaluated in yogurt during storage at $4{ }^{\circ} \mathrm{C}$. Furthermore, we carried out the microbiological analysis of 7-, 14-, 21 and 28-day stored yogurts in order to monitor the capability of strains to persist in the dairy product during a simulated period of shelf life. Finally, the ability of the Lactobacillus strains tested to survive 
in the human digestive tract and their effects on the transcriptional level of several genes involved in the immune response using LPS-stimulated monocytoid THP-1 cells as a model were analyzed.

\section{Results and Discussion}

\subsection{Chemical Analysis}

The chemical composition of milk used in all experiments was determined prior to the fermentation processes and was as follows: fat $3.6 \% \pm 0.1 \%$, protein $3.3 \% \pm 0.2 \%$, lactose $4.7 \% \pm 0.1 \%$ and casein $2.5 \% \pm 0.1 \%$. Furthermore, the yogurt samples were analyzed for their $\mathrm{pH}$, lactic acid, protein, casein, nitrogen fractions, fat content and peptide profile in order to investigate the influence by different strains of L. plantarum on yogurt fermentation over 1,14 and 28 days of storage at $4{ }^{\circ} \mathrm{C}$ (Table 1 ).

Table 1. Chemical composition of yogurt.

\begin{tabular}{ccccccc}
\hline Stain & pH & Prot $(\%)$ & Casein (\%) & WSEs (\%) & Fat (g/100 g) & Lactic acid (g/L) \\
\hline \multicolumn{5}{c}{ l Day } \\
\hline CNT & $4.19 \pm 0.01$ & $3.28 \pm 0.11$ & $2.45 \pm 0.11$ & $0.15 \pm 0.01$ & $2.68 \pm 0.17$ & $3.98 \pm 0.35$ \\
LpWCFS1 & $4.07 * \pm 0.02$ & $3.43 \pm 0.11$ & $2.41 \pm 0.11$ & $0.19 \pm 0.01$ & $3.75 * \pm 0.39$ & $4.43 \pm 0.65$ \\
Lp8328 & $4.28 * \pm 0.01$ & $3.35 \pm 0.23$ & $2.59 \pm 0.16$ & $0.19 \pm 0.01$ & $4.05 * \pm 0.13$ & $4.65 \pm 1.04$ \\
\hline \multicolumn{5}{c}{14 Days } \\
\hline CNT & $4.25 \pm 0.01$ & $3.03 \pm 0.00$ & $2.42 \pm 0.00$ & $0.11 \pm 0.01$ & $4.43 \pm 0.10$ & $4.90 \pm 0.81$ \\
LpWCFS1 & $4.18 * \pm 0.01$ & $2.95 \pm 0.11$ & $2.34 \pm 0.11$ & $0.10 \pm 0.00$ & $4.48 \pm 0.10$ & $5.05 \pm 0.04$ \\
Lp8328 & $4.13 * \pm 0.01$ & $3.19 * * \pm 0.00$ & $2.27 \pm 0.14$ & $0.12 \pm 0.00$ & $4.45 \pm 0.06$ & $5.43 \pm 0.51$ \\
\hline \multicolumn{5}{c}{28 Days } \\
\hline CNT & $4.22 \pm 0.01$ & $1.99 \pm 0.11$ & $1.61 \pm 0.07$ & $0.10 \pm 0.00$ & $4.3 \pm 0.20$ & $5.14 \pm 0.23$ \\
LpWCFS1 & $4.17 * \pm 0.01$ & $2.87 * \pm 0.00$ & $2.24 * \pm 0.02$ & $0.10 \pm 0.00$ & $4.4 \pm 0.00$ & $5.46 \pm 0.62$ \\
Lp8328 & $4.21 \pm 0.01$ & $2.95 * \pm 0.11$ & $2.13 * \pm 0.11$ & $0.12 \pm 0.00$ & $4.3 \pm 0.20$ & $5.44 \pm 0.26$ \\
\hline
\end{tabular}

Prot, Protein content; WSE, water-soluble extracts; CNT, positive control fermented with S. thermophilus and L. delbrueckii ssp. bulgaricus; LpWCFS1, yogurt fermented with S. thermophilus, L. delbrueckii ssp. bulgaricus and L. plantarum WCFS1; Lp8328, yogurt fermented with S. thermophilus, L. delbrueckii ssp. bulgaricus and L. plantarum CECT 8328. Values represent the mean \pm the standard deviation (SD). Statistical analyses were carried out by the Student's $t$-test, and significant differences are relative to the control sample $(* p<0.05$ and $* * p<0.005)$.

The results showed that the $\mathrm{pH}$ values of the control yogurt (fermented only by starter strains without any inoculation with $L$. plantarum strains) were 4.19, 4.25 and 4.22 after 1, 14 and 28 days of storage, respectively. The yogurt samples inoculated with L. plantarum WCFS1 and L. plantarum CECT 8328 presented $\mathrm{pH}$ values after 1 and 14 days of storage significantly different from the control. However, these differences disappeared after 28 days of storage for L. plantarum CECT 8328, while for the yogurt inoculated with $L$. plantarum WCFS1, the $\mathrm{pH}$ values remained significantly lower ( $\mathrm{pH} 4.17$ ), even after 28 days. Frequently, the $\mathrm{pH}$ of yogurt drops during storage, the so-called post-acidification problem, and this can lead to a loss of organoleptic quality. Commonly, consumers prefer yogurts presenting mild acidity ( $\mathrm{pH} 4.2-4.4$ ); thus, microbial cultures with a mild acid production ability are usually selected in order to obtain yogurts with mild acidity and $\mathrm{pH}$ stability during shelf-life [22,23]. Interestingly, all of 
our strains, once fermentation had been carried out during yogurt production, did not cause further lowering of $\mathrm{pH}$ in the yogurt samples over the entire storage time.

The protein fraction was also quantified, and as the average, its content was around $3.43 \%$ and $2.95 \%$ after 1 day and 14 days, with no significant differences among the collected samples. However, a higher percentage of protein $(3.19 \%)$ was observed, after 14 days, for the yogurt inoculated with L. plantarum CECT 8328. Nevertheless, after 28 days of storage, the protein contents of all yogurts inoculated with L. plantarum strains were significantly higher $(2.87 \%$ and $2.95 \%$ for $L$. plantarum WCFS1 and L. plantarum CECT 8328) than the amount measured in the control sample (1.99\%).

The percentage of casein decreased in a time-dependent manner for all of the samples analyzed. However, the ability to degrade casein was reduced in the yogurt inoculated with L. plantarum WCFS1 and L. plantarum CECT 8328 compared to the control sample.

The total soluble nitrogen content decreased during the storage, possibly due to the proteolytic activity of bacteria, without any significant differences between the trials. Similarly, no significant differences were observed for fat and lactic acid content over medium and long storage times. As the average, the lactic acid content was 4.51, 5.01 and 5.1 g/L after 1, 14 and 28 days, respectively.

Overall, the results reported suggested that the yogurts fermented with $S$. thermophilus and L. delbrueckii ssp. bulgaricus co-inoculated with L. plantarum strains led to the final product showing a different $\mathrm{pH}$ value over small and medium, but not long, storage times. Moreover, the inoculated samples presented higher protein and casein content compared to the control. Conversely, the percentage of water-soluble extracts (WSEs) and fat and the lactic acid amount after 14 and 28 days were similar to the control.

During the milk fermentation, lactic acid bacteria are involved in casein proteolysis in order to provide the amino acids and peptides needed for their growth. Thus, the molecule accumulation in the final fermented product depends on the hydrolase pathways possessed by selected strains of bacteria. Consecutively, the peptide profile may influence the nutrition quality of the fermented product and may condition the growth of other co-inoculated microorganisms [24]. For instance, it is known that the gradual degradation of peptides by the yogurt starter L. bulgaricus cultures promotes the growth of S. thermophilus, which more rapidly produces lactic acid $[25,26]$. Here, we analyzed the WSE during the storage of yogurt fermented with different Lactobacilli strains co-inoculated with the two yogurt starter cultures, S. thermophilus and L. bulgaricus subsp. delbrueckii. The results from RP-HPLC (Figure 1a-c) showed a basically similar peptide profile for all treatments with quantitative differences for the peptide content of the water-soluble extracts over storage time (increasing in a time-dependent manner). Compared with the control, L. plantarum CECT 8328 was the most proteolytic strain. Principal component analysis (PCA) was used to analyze the clustering of the treatments. As reported in Figure 1d, the peptide profiles of $L$. plantarum CECT 8328 and L. plantarum WCFS1 were different from those observed for the control samples. 


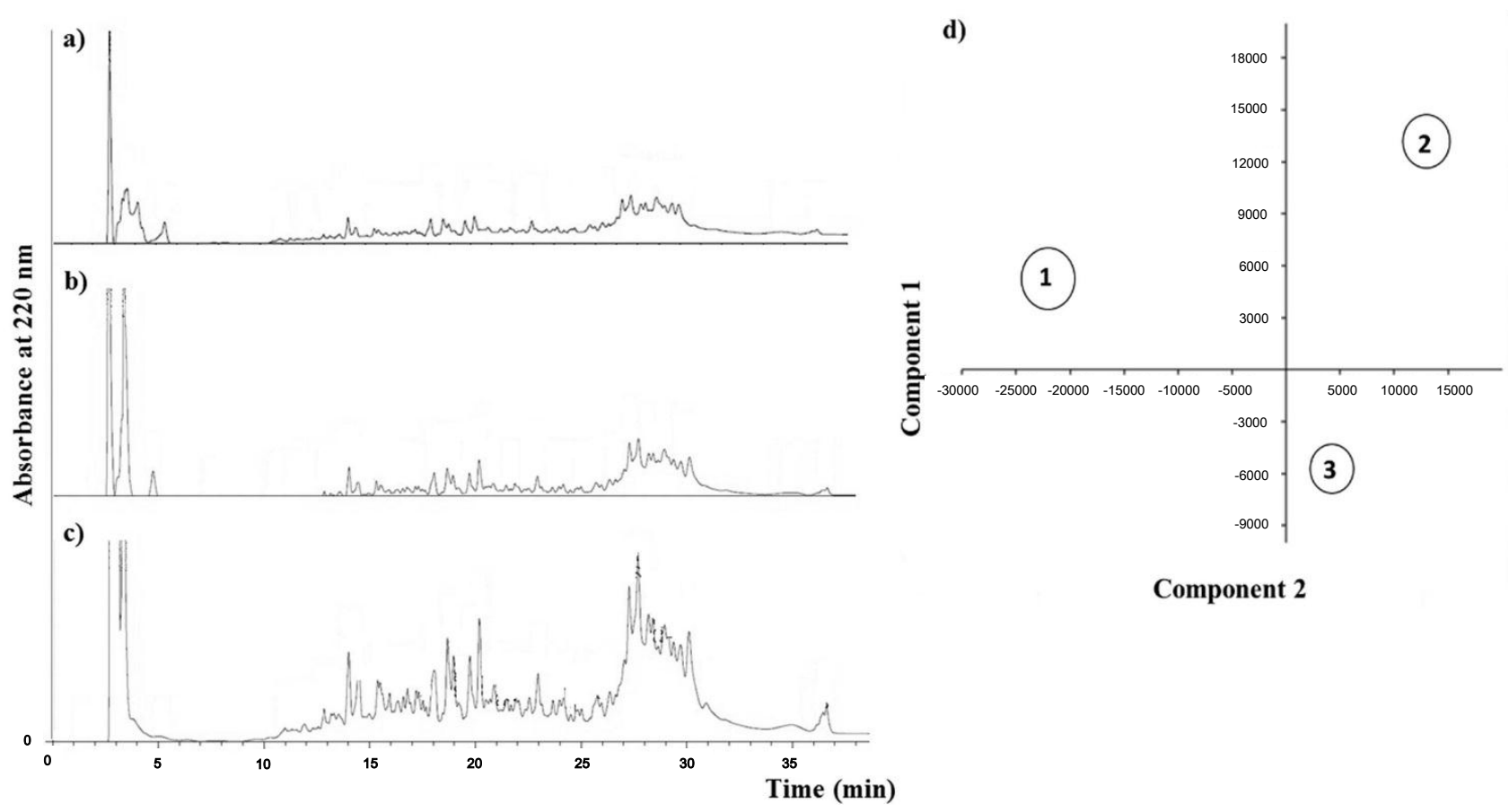

Figure 1. Representatives RP-HPLC profiles of the water-soluble extracts (WSEs) and PCA obtained from the yogurt studied in this work. The chromatograms are relative to yogurt fermented with only S. thermophilus and L. delbrueckii ssp. bulgaricus (CNT) after 1 (a), 14 (b) and 28 (c) days of storage. PCA plots (d) were based on the analysis of all peptide profiles of all yogurt samples. CNT, 1; L. plantarum WCFS1, 2; L. plantarum CECT 8328, 3.

\subsection{Viability of Lactobacillus plantarum Strains}

We used the Q-PCR-propidium monoazide (PMA) methodology to investigate the viability of L. plantarum strains. The use of PMA associated with Q-PCR has been shown to be valuable for discriminating between live and dead microorganisms [27]. PMA selectively penetrates the membranes of dead cells and links the dsDNA. The dsDNA-PMA complex can be activated by light and bind the cellular hydrocarbon moiety to form highly-stable compounds. The dsDNA-PMA-hydrocarbon complex is left out during Q-PCR amplification; thus, the DNA of dead cells is not detected.

In this study, the viability of $L$. plantarum strains for every yogurt sample was analyzed at Time 0 (initial inoculum prior to the start of the fermentation), 1, 14, 21 and 28 days of storage. As shown in Figure 2, the CFU/mL of each Lactobacilli strain decreased in a time-dependent manner with no significant differences after 1, 7 and 14 days. However, we observed a significantly higher cell survival for the vitamin over-producing strain, L. plantarum CECT 8328, after 21 and 28 days with respect to L. plantarum WCFS1. Overall, microbial counts during the storage were higher than $10^{8} \mathrm{CFU} / \mathrm{mL}$, according to the probiotic recommended threshold to confer beneficial effects to humans [28]. 


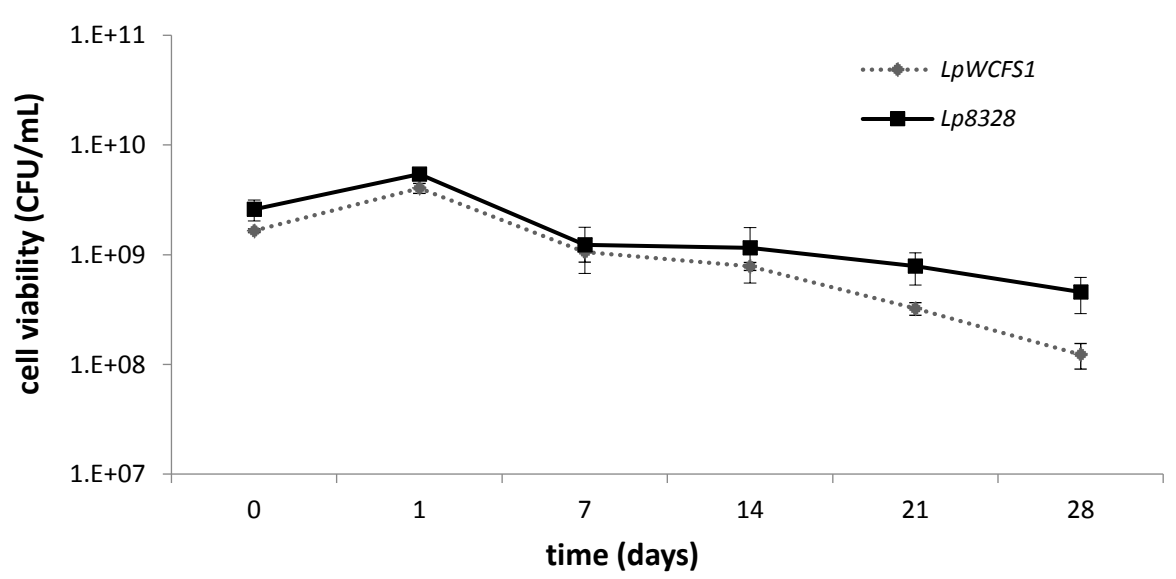

Figure 2. Cell viability of L. plantarum strains used to produce yogurt at Time 0 (initial inoculum prior to the start of the fermentation), 1, 14, 21 and 28 days of storage at $4{ }^{\circ} \mathrm{C}$. LpWCFS1, L. plantarum WCFS1; Lp8328, L. plantarum CECT 8328. Values represent the mean \pm the standard deviation (SD) of two different experiments.

\subsection{Oro-Gastrointestinal Tolerance Assay}

The capability of L. plantarum WCFS1 and L. plantarum CECT 8328 inoculated into yogurt matrix to endure human digestion was also investigated by an in vitro simulation of the gastrointestinal tract (oral, gastric and intestinal conditions) [29].

The results indicated variable survival percentages depending on the strains and the gastrointestinal stress steps (Figure 3). The bacterial percentage of survival with respect to untreated samples was not influenced by oral stress. Conversely, the persistence of Lactobacilli strains was mainly affected under gastric conditions in a $\mathrm{pH}$-dependent manner, similar to the results obtained by other authors [29-31]. These findings are correlated with the greater difficulty of bacteria to resist low $\mathrm{pH}$ and underlined the necessity to select probiotic bacteria with a strong ability to tolerate acid environments in order to overcome the gastric sector and reach the intestine. The percentage of cell survival of L. plantarum WCFS1 and L. plantarum CECT 8328 after exposure to gastric stress at pH 3.0 decreased by about $1 \log$ unit and $2.5 \mathrm{log}$ units, respectively. However, the percentage of survival of L. plantarum CECT 8328 was significantly higher than that of L. plantarum WCFS1 after gastric stress at pH 2.0 and under intestinal stresses (Figure 3). 


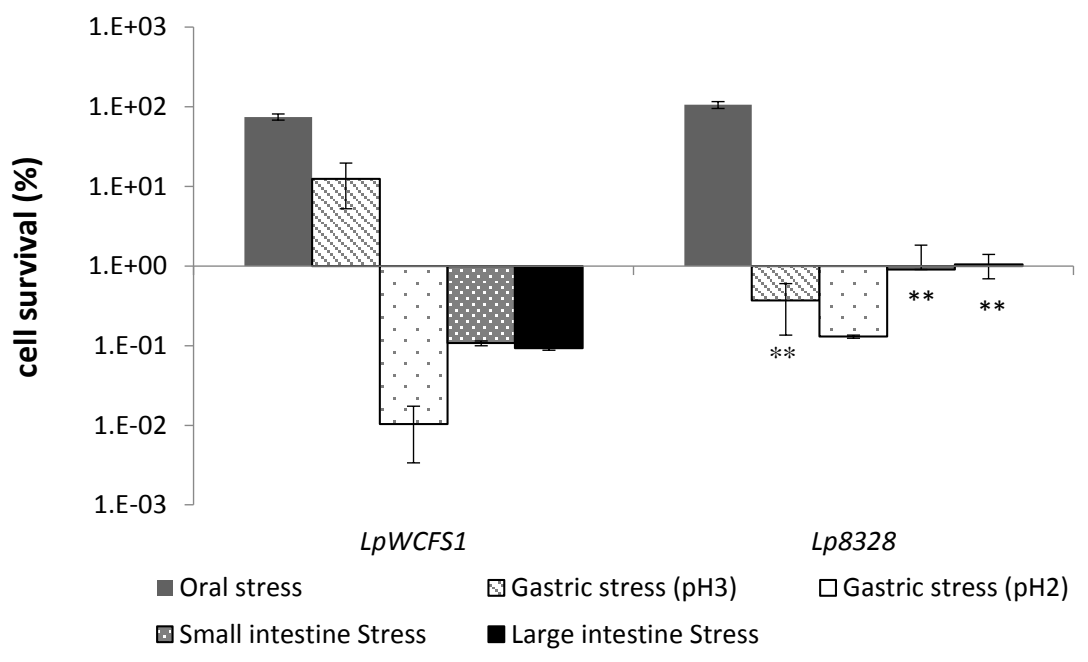

Figure 3. Bacterial survival after exposure of L. plantarum strains inoculated in yogurt to an in vitro model simulating the human oro-gastrointestinal tract (oral, gastric pH 3.0 and $\mathrm{pH} 2.0$ and small and large intestine stresses). Viability was calculated as the percent of survival relative to the untreated control (i.e., the sample before the simulated digestion). Values represent the mean \pm the standard deviation of three different experiments. Statistical analyses were carried out by the Student's $t$-test, and significant differences are relative to the probiotic L. plantarum WCFS1 strain (* $p<0.05$ and $* * p<0.005)$. LpWCFS1, L. plantarum WCFS1; Lp8328, L. plantarum CECT 8328.

\subsection{Stimulation of THP-1 Cells with Lactobacillus plantarum Strains}

The human gastrointestinal system fulfils the important role of metabolizing and absorbing the nutrients indispensable for cell growth and activity. Furthermore, the gut acts also as a central component of the immune system, both performing the function of a physical barrier and producing different types of immune mediators essential to maintaining the immune homeostasis $[9,10]$. However, malfunctions of immune homeostasis with continuous release of pro-inflammatory cytokines can result in a persistent inflammation process that can lead to intestinal dysfunction, cell damage and chronic inflammatory gut disease, such as Crohn's disease (CD) and ulcerative colitis (UC), as well as several multiple disease states [12,32]. The capability of diet components, including functional food containing probiotic bacteria, to modulate the immune-related genes could ameliorate and/or prevent the intestinal inflammatory conditions. In this context, the potential ability of probiotic strains inoculated in yogurt to influence the expression level of genes involved in immunomodulation was investigated. Since food consumed by diet is exposed to several digestive steps to be metabolized, we carried out the assays exposing THP-1 cells to both untreated and in vitro digested yogurt samples containing L. plantarum strains, in order to understand whether the in vitro digestion could affect the immunomodulation activity. The components of bacterial cell walls, peptidoglycan (PG), present in both Gram-positive and Gram-negative bacteria, and lipopolysaccharide (LPS), present in Gram-negative microorganisms, may stimulate the human cells in a receptor-dependent process activating the release of several immune mediators. For instance, LPS-activated macrophages can produce cytokines, such as interleukins (IL-8, IL1 $\beta$, IL-6) and/or tumor necrosis factor- $\alpha$ (TNF- $\alpha$ ), involved in the immune response [33]. For this reason, we exposed the differentiated THP-1 cells to only LPS (positive control) and LPS-sample in 
order to compare the transcriptional level of several genes involved in the regulation of the immune response, i.e., IL-8, TNF- $\alpha$, IL1 $\beta$, TSLP, IL-6, NF- $\kappa$ B1 and IL-10. Cytokines play a crucial role in the inflammatory process, being able to coordinate the initiation, amplification and interruption of immune response [16]. As shown in Figure 4, the relative expression of genes involved in cytokine-mediated signaling was globally affected by exposure to the sample containing Lactobacilli in a strain- and time-dependent manner. The transcriptional levels of IL-8 were significantly reduced by all samples, both undigested and in vitro digested samples. We observed a slightly higher ability of undigested samples to moderate the transcriptional level of IL-8 gene after $1 \mathrm{~h}$ of incubation with respect to the in vitro digested samples. Conversely, this trend was not noted after $4 \mathrm{~h}$ of exposure, where the in vitro digested samples containing Lactobacilli were mostly able to moderate the expression of IL-8. IL-8, a potent cytokine, is involved in host defense by the activation and chemo-attraction of neutrophils. High levels of IL-8 are associated with inflammatory diseases and conditions, such as asthma, inflammatory bowel disease (IBD) and exposure to LPS of Gram-negative bacteria [34]. In this study, the transcriptional analysis showed that the probiotic bacteria inoculated in food matrix were able to downregulate the gene expression of IL-8.

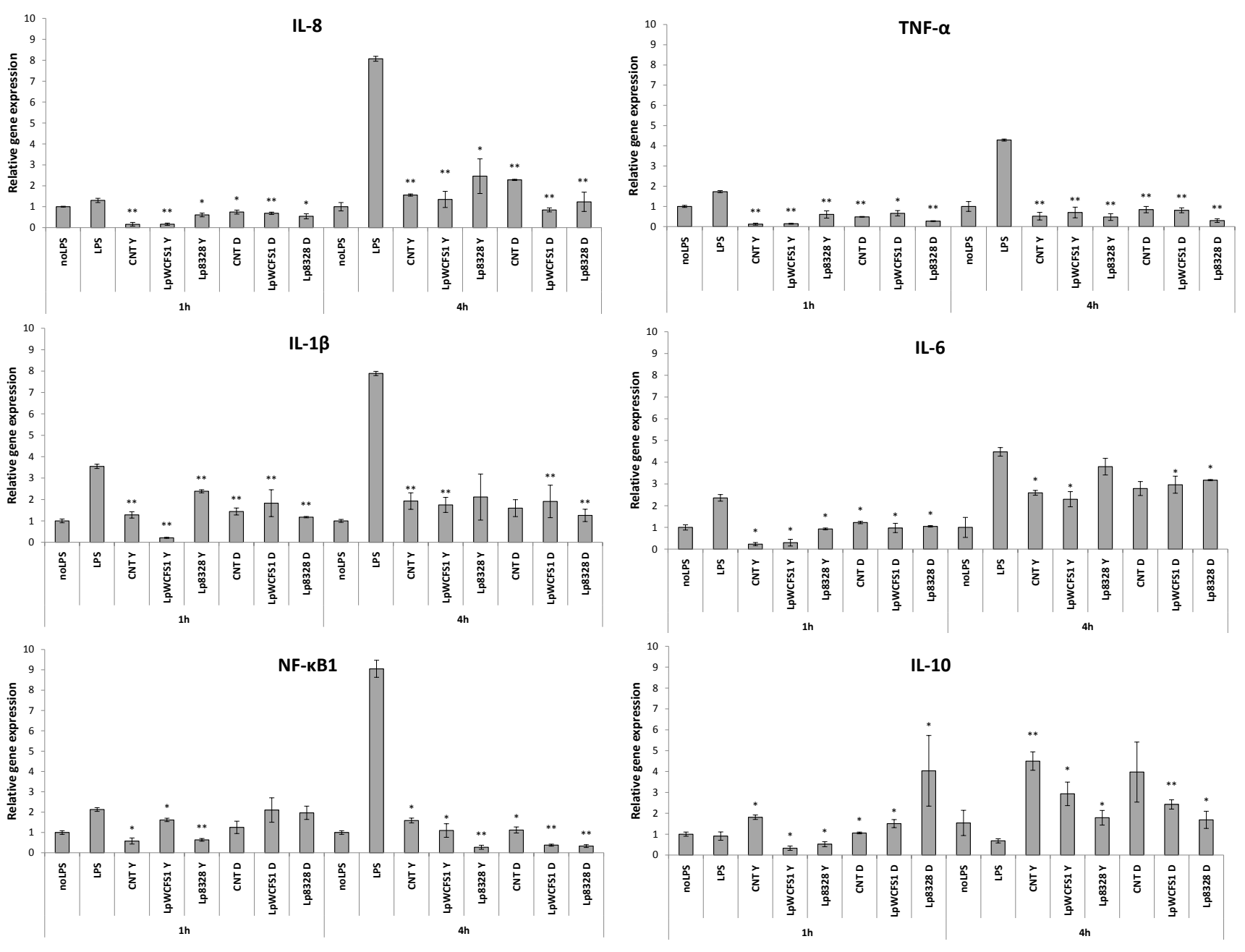

Figure 4. Cont. 


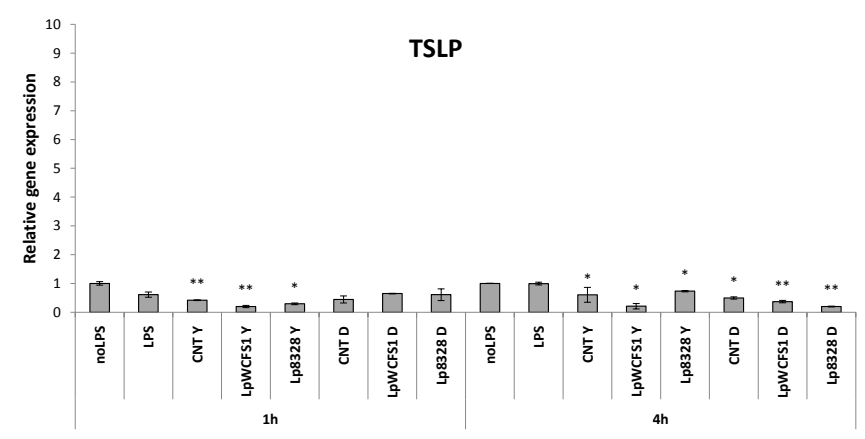

Figure 4. Relative expression of cytokine-related genes after the exposure to undigested (Y) and in vitro digested (D) samples containing Lactobacilli strains over $1 \mathrm{~h}$ and $4 \mathrm{~h}$ of treatments. Values represent the mean \pm the standard deviation of two different experiments. Statistical analyses were carried out by the Student's $t$-test, and significant differences are relative to LPS-stimulated THP-1 cells without strains (LPS, positive control) $(* p<0.05$ and $* * p<0.005)$. noLPS, no LPS-stimulate THP-1 cells used as negative control; CNT, yogurt inoculated with $S$. thermophilus and L. bulgaricus subsp. delbrueckii was the matrix control; LpWCFS1, yogurt inoculated with S. thermophilus, L. bulgaricus subsp. delbrueckii and L. plantarum WCFS1; Lp8328, yogurt inoculated with S. thermophilus, L. bulgaricus subsp. delbrueckii and L. plantarum CECT 8328.

The strongest activators of the IL- 8 gene are the pro-inflammatory cytokines, tumor necrosis factor- $\alpha($ TNF- $\alpha)$ and interleukin $1 \beta$ (IL-1 $\beta$ ) [34]. Moreover, TNF- $\alpha$ is able to coordinate the enhancement of the inflammatory response by activating neutrophils, mononuclear phagocytes and other cell types, such as eosinophils $[33,35,36]$. IL-1 $\beta$ belongs to the IL1 family, which plays an important role in the cascade response of the innate immune system, incrementing cytokine production in dendritic cells, stimulating phagocytosis in macrophages and increasing oxidative burst and protease release in neutrophils, which promote the differentiation and proliferation of T-cells [37]. In the case of TNF- $\alpha$ gene analysis, our results showed a significant reduction of expression both after $1 \mathrm{~h}$ and $4 \mathrm{~h}$ of exposure for all treatments with samples containing probiotic bacteria without significant differences between undigested and in vitro digested trials. Similarly, we found a downregulation of the transcriptional levels of the IL-1 $\beta$ gene after $1 \mathrm{~h}$ and $4 \mathrm{~h}$ of incubation.

Another multifunctional cytokine implicated in pro- and in several anti-inflammatory processes is interleukin 6 (IL-6), which is highly produced in response to pathogen infections, the growth of normal and neoplastic cells and also after LPS-induction [4]. In this study, the IL-6 gene expression was significantly reduced by exposure to all samples containing Lactobacilli with respect to the control (only LPS). However, we observed that the transcription level of IL-6 was more quickly decreased after a shorter time of exposure $(1 \mathrm{~h}$ ) compared to longer incubation with probiotics $(4 \mathrm{~h})$. Moreover, we showed a marginally higher capacity of undigested samples to reduce IL- 6 gene expression with respect to the in vitro digested samples after $1 \mathrm{~h}$. Contrariwise, this trend was not noted after $4 \mathrm{~h}$ of exposure, because the in vitro digested samples inoculated with Lactobacilli were mostly able to moderate the expression of IL-6, similarly to the results obtained for IL- 8 gene analysis. These results are in agreement with previous studies by Riedel et al. [38], where strains of Bifidobacterium longum and Bifidobacterium bifidum were shown to reduce the transcriptional level of IL- 8 and TNF- $\alpha$ genes in the HT-29 cell line. 
Other authors demonstrated that several probiotic microorganisms induced a dramatic reduction of the secretion of IL-8 protein in HT-29 cells, highlighting their anti-inflammatory effects [19,39]. Furthermore, strains belonging to Kluyveromyces, Lactobacillus and Bifidobacterium genera were shown to determine the decrease in the secretion level of the pro-inflammatory cytokines, IL-8, IL-6 and TNF- $\alpha[12,40]$. In addition, diminution of IL-6 levels was demonstrated when probiotic Lactobacilli strains were co-cultured with the pathogenic bacteria, Escherichia coli [4].

During an inflammatory reaction, the most important transcription factors of cytokine-mediated pro-inflammatory genes, e.g., IL-8, TNF- $\alpha$, IL-1 $\beta$, IL-6, are the nuclear factor $\kappa b(\mathrm{NF}-\kappa \mathrm{B})$ proteins

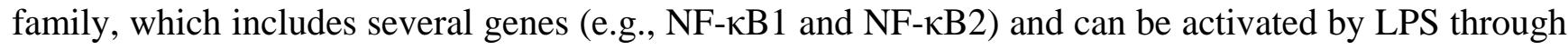
specific receptors, called toll-like receptors 4 (TLR4). There are several pieces of evidence that the expression of TLR4 and then NF- $\kappa \mathrm{B}$ genes is aberrant in chronic intestinal disease, which provokes strong inflammatory conditions, i.e., IBD. Contrarily, in healthy patients, the TLR4 and NF- $\kappa \mathrm{B}$ expression is at very low levels [4]. As shown in Figure 4, the exposure of samples inoculated with L. plantarum strains to LPS-stimulated THP-1 cells indicated that the tested Lactobacilli inhibited the activation of the NF- $\mathrm{NB} 1$ gene, except for some treatments after $1 \mathrm{~h}$ of exposure (in vitro digested sample inoculated with $L$. plantarum CECT 8328). We speculate that a longer time of incubation could be necessary to determine a higher reduction of that gene expression. In fact, the increment of transcriptional level was also increased by LPS mainly after $4 \mathrm{~h}$ (around nine-fold) with respect to shorter incubation of $1 \mathrm{~h}$ (around two-fold).

Whereas the immune system contrasts the origin of injury or infection rousing the production of many pro-inflammatory molecules during an inflammatory process, the complex immune network, when it have removed the enemy, provides also the restoring of the immune homeostasis, inducing anti-inflammatory cytokines. The gene coding for interleukin 10 (IL-10) can mediate the downregulation of inflammatory progression [10]. In this study, we reported a relevant increase of the expression of IL10 by probiotic bacteria for all in vitro digested samples after $1 \mathrm{~h}$ and for all treatments after $4 \mathrm{~h}$ of exposure. However, we noted a slight reduction of transcriptional level after $1 \mathrm{~h}$ of incubation by undigested samples, supposedly due to the presence of undigested yogurt matrix during the assay. Similar to our results, Cui et al. [41] studied the effects of probiotics on the intestinal mucosa of patients with ulcerative colitis (UC) and demonstrated that probiotics were able to enhance the expression of the anti-inflammatory cytokine IL-10 and to decrease the activation of NF- $\kappa \mathrm{B}$, reducing the expressions of TNF- $\alpha$ and IL- $1 \beta$ genes. The authors suggested the potential use of their probiotic preparation to contrast the flare-ups of chronic UC.

Lastly, we investigated the ability of the tested probiotics to influence the expression level of the thymic stromal lymphopoietin (TSLP) gene. TLSP is involved in the allergic response, i.e., bowel ulcerative colitis (UC) and Crohn's disease, but also in asthma and dermatitis events. During those inflammatory processes, the transcriptional level of TSLP is upregulated $[42,43]$. TNF- $\alpha$ and IL-1 $\beta$ are able to control the induction of TSLP expression [44], but it may be alternatively increased via other pathways [43]. TSLP have been also shown to have a role in the tumor development of intestinal cells [45]. With respect to the TSLP gene, we found that the exposure of LPS-stimulated THP-1 cells to food matrix containing L. plantarum strains resulted in a decrease in the gene transcription occurring within $4 \mathrm{~h}$, showing no increments of gene expression by treatments. Plausibly, the fact that probiotics 
may modulate the TSLP gene expression promotes a suitable application of these beneficial microbes as immune-modulators.

Comprehensively, the transcriptional analysis of cytokine-mediating genes showed that the probiotic bacteria used in this study have a favorable influence on immunomodulation. Overall, we did not find significant differences between undigested and in vitro digested treatments; thus, we concluded that the effects on immune stimulation were unrelated to digestive processes.

\section{Experimental Section}

\subsection{Bacterial Strains, Human Cells and Growth Conditions}

The bacterial strains used in this work were Lactobacillus plantarum CECT 8328, a strain already characterized for its probiotic features and ability to over-produce riboflavin in a co-culture system with Caco-2 cells [29], the probiotic Lactobacillus plantarum WCFS1 [46], Streptococcus thermophilus UFG24 and Lactobacillus delbrueckii ssp. bulgaricus UFG23, which were isolated from a homemade yogurt and identified by $16 \mathrm{~S}$ ribosomal DNA amplification (data not shown).

L. plantarum, S. thermophilus and L. delbrueckii ssp. bulgaricus strains were propagated in de Man Rogosa Sharpe (MRS, Oxoid, Basingstoke, UK) (pH 6.2) and incubated at $30{ }^{\circ} \mathrm{C}$ (L. plantarum strains) and $42{ }^{\circ} \mathrm{C}$ (L. delbrueckii and $S$. thermophilus strains), respectively.

Human monocytoid leukemia-derived cells (THP-1) (Sigma-Aldrich, St. Louis, MO, USA) were grown in RPMI-1640 (Sigma-Aldrich) supplemented with 10\% (v/v) FBS, 2 mM L-glutamine, $100 \mathrm{U} / \mathrm{mL}$ penicillin and $100 \mu \mathrm{g} / \mathrm{mL}$ streptomycin, in atmosphere containing $5 \% \mathrm{CO}_{2}$ at $37{ }^{\circ} \mathrm{C}$. Then, THP-1 cells were seeded at concentration of $5 \times 10^{5}$ cells/well in 24-wells plates, resuspended in RPMI 1640 medium without any supplements and induced to differentiate into a mature macrophage-like state by treating for $48 \mathrm{~h}$ with $100 \mathrm{ng} / \mathrm{mL}$ phorbol 12-myristate 13-acetate (PMA) (Sigma-Aldrich).

\subsection{Yogurt Fermentation}

Yogurt was made from cow's milk according to [47]. Briefly, the milk was heat-treated at $85{ }^{\circ} \mathrm{C}$ for $30 \mathrm{~min}$, and the absence of microorganisms was ascertained by counting of CFU/mL on MRS agar plates. All bacteria strains, including L. plantarum WCFS1, L. plantarum CECT 8328, S. thermophilus and L. delbrueckii ssp. bulgaricus, were pre-incubated overnight, then centrifuged $(2000 \times g, 10 \mathrm{~min})$. The media was decanted, and the pellets were resuspended directly in milk to obtain a final concentration of $1 \times 10^{9} \mathrm{CFU} / \mathrm{mL}$. We carried out three different milk fermentations using the following combinations: (1) S. thermophilus and L. delbrueckii ssp. bulgaricus (positive control); (2) S. thermophilus, L. delbrueckii ssp. bulgaricus and L. plantarum WCFS1; and (3) S. thermophilus, L. delbrueckii ssp. bulgaricus and L. plantarum CECT 8328. All samples were then incubated at $42{ }^{\circ} \mathrm{C}$ for $6 \mathrm{~h}$ and then stored at $4{ }^{\circ} \mathrm{C}$ for 28 days. All trials were performed in duplicate.

\subsection{Chemical Analysis}

Milk samples were analyzed for fat, protein, lactose and casein content (MilkoScanTM, FT 120; Foss Electric, Hillerǿd, Denmark). Yogurt samples were analyzed after 1, 14 and 28 days of storage for protein, casein and nitrogen fractions by the Kjeldahl method according to the AOAC method [48] and 
for fat contents by the Gerber method according to the British Standards Institution [49]. The lactic acid content was detected by enzymatic kits according to the manufacturer's instructions (Biogamma s.r.1, Roma, Italy).

For monitoring the hydrolysis of protein during storage of yogurt at $4{ }^{\circ} \mathrm{C}$, the $\mathrm{pH} 4.6$ water-soluble extracts (WSEs) of the samples were prepared according to the method proposed by Kuchroo and Fox [50].

The peptide profiles of the WSEs were determined by reverse-phase high performance liquid chromatography (RP-HPLC) using Agilent 1260 Infinity (Agilent Technologies, Santa Clara, CA, USA). The column used was a ZORBAX $300 \mathrm{SB}-\mathrm{C} 18(250 \mathrm{~mm} \times 4.6 \mathrm{~mm} \times 5 \mu \mathrm{m})$ (Agilent). The mobile phase was water (Solvent A) and acetonitrile (Solvent B), both containing $0.1 \%$ trifluoroacetic acid, and the solvent flow rate was $1 \mathrm{~mL} / \mathrm{min}$. The eluate was monitored at wavelength of $220 \mathrm{~nm}$; all solvents were of chromatography grade (Baker, Inc., Phillipsburg, NJ, USA).

\subsection{Microbiological Analysis}

The viability of L. plantarum WCFS1 and L. plantarum CECT 8328 was monitored in all samples prior to fermentation (T0) and following fermentation after 1, 714,21 and 28 days by quantitative real-time PCR (see below).

\subsection{Oro-Gastrointestinal Tolerance Assay}

Yogurt samples after 14 days of storage (as an intermediate shelf-life time) were exposed to a simulated oro-gastrointestinal transit, as described by Arena et al. [29]. Aliquots taken prior to the oro-gastrointestinal assay and after the oral, gastric ( $\mathrm{pH} 2.0$ and 3.0) and intestinal (small and large intestine sectors) stresses were used for the evaluation of bacterial survival, monitored by quantitative real-time PCR. The percentage of survival was determined with respect to the unstressed control. The samples, after the last step of intestinal tract stress (large intestinal compartment), were used for the stimulation of THP-1 cells assay.

\subsection{Stimulation of THP-1 Cells with Lactobacilli}

To perform the immunostimulation assay, both untreated (yogurt samples that were not exposed to the in vitro digestion assay) and in vitro digested yogurt samples were used. To decide the ratio of bacteria:human cells to be used, we considered two main aspects. Firstly, the percentage of cell survival after the entire in vitro digestion assay was around $1 \times 10^{6} \mathrm{CFU} / \mathrm{mL}$ for L. plantarum WCFS1 and around $1 \times 10^{7} \mathrm{CFU} / \mathrm{mL}$ L. plantarum CECT 8328 . Secondly, the digestion solutions and enzymes used in the in vitro digestion can affect human cell viability; thus, the samples need to be diluted in a ratio of $1: 3$ (sample:medium) [51]. Hence, bacteria pellets were harvested by centrifugation $(2000 \times g$ for $10 \mathrm{~min})$ and resuspended in RPMI 1640 medium. The final concentration for L. plantarum WCFS1 was $3 \times 10^{5} \mathrm{CFU} / \mathrm{mL}$ (both for untreated and in vitro digested samples), and for L. plantarum CECT 8328, this was around $3 \times 10^{6} \mathrm{CFU} / \mathrm{mL}$ (both for untreated and in vitro digested samples).

Macrophage-differentiated THP-1 cells were treated as described elsewhere [19]. Briefly, THP-1 cells were exposed to $100 \mathrm{ng} / \mathrm{mL}$ of lipopolysaccharide (LPS) from E. coli O127:B8 (Sigma). Our 
samples (untreated and in vitro digested samples appropriately diluted) were added and incubated for 1 and $4 \mathrm{~h}$ at $37{ }^{\circ} \mathrm{C}$ with $5 \% \mathrm{CO}_{2}$. Positive and negative controls were macrophage-differentiated THP-1 cells incubated with and without LPS, respectively. Human cells were harvested, and transcriptional analysis was performed for genes coding immune-related genes (see below).

\subsection{Propidium Monoazide Treatment and Microbial DNA Extraction}

Yogurt samples were treated with propidium monoazide (PMA), as previously described by Àlvarez et al. [27]. Briefly, $100 \mu \mathrm{M}$ of PMA (Biotium, Inc., Hayward, CA, USA) dissolved in 20\% of dimethylsulfoxide (DMSO) (Sigma) were added to $1 \mathrm{~mL}$ of yogurt samples and kept in light-transparent 1.5-mL microcentrifuge-tubes. The tubes were incubated in dark conditions for $10 \mathrm{~min}$ and then exposed to a halogen lamp (650 W, $230 \mathrm{~V}$, GY 9.5, $3050 \mathrm{~K}$; Philips, Tokyo, Japan).

Successively, the genomic DNA of each strain was extracted from the yogurt samples pre-treated by PMA, as reported by Quigley [52], using a lytic method. Briefly, $1 \mathrm{~mL}$ of each sample was added to $0.5 \mathrm{~mL}$ of breaking buffer for enzymatic lysis and incubated at $37^{\circ} \mathrm{C}$ for $1 \mathrm{~h}$. Subsequently, the samples were treated with proteolytic enzyme by adding $250 \mu \mathrm{g} / \mathrm{mL}$ of proteinase $\mathrm{K}$ and incubating at $55^{\circ} \mathrm{C}$ for $1 \mathrm{~h}$. The suspension was transferred to a new tube containing zirconium beads, shaken twice for $90 \mathrm{~s}$ and centrifuged at $12,000 \times g$ for $10 \mathrm{~min}$. The supernatant was added to an equal volume of phenol:chloroform:isoamyl alcohol (25:24:1), mixed gently and centrifuged at $12,000 \times g$ for 2 min. Only the upper aqueous phase was transferred into a clean tube. Sodium acetate ( $3 \mathrm{M}$ ) (one-tenth the volume) and $100 \%$ ice-cold ethanol ( 2 volumes) were added. The samples were mixed, stored at $-20{ }^{\circ} \mathrm{C}$ overnight and then centrifuged at $14,000 \times g$ for $10 \mathrm{~min}$ in order to harvest the pellet that was washed with $70 \%$ ice-cold ethanol followed by centrifugation at $12,000 \times g$ for $5 \mathrm{~min}$ and dried. The final pellet was resuspended in $100 \mu \mathrm{L}$ TE buffer and used in Q-PCR detection.

\subsection{THP-1 RNA Extraction and Reverse Transcription}

RNA extraction, cDNA synthesis and quantitative RT-PCR were performed as previously described [53]. Briefly, THP-1 macrophages were harvested with TRIzol reagent (Invitrogen, Carlsbad, CA, USA). The total RNA was extracted according to the manufacturer's instructions. The RNA concentration and integrity were determined by spectrophotometry (Biotek Instruments, Winooski, VT, USA) and gel electrophoresis. One microgram of total RNA was reverse-transcribed using the QuantiTect Reverse Transcription kit (Qiagen, Valencia, CA, USA).

\subsection{Q-PCR Analysis}

The extracted microbial DNA were diluted (1:20), and $5 \mu \mathrm{L}$ were used to perform the Q-PCR analysis (ABI 7300, Applied Biosystems, Foster City, CA, USA) in a reaction mixture containing $15 \mu \mathrm{L}$ of PCR mix (Power SYBR Green PCR Master Mix; Applied Biosystems) and $100 \mathrm{nM}$ of forward and reverse primers for gyrA amplification specific for L. plantarum species [54]. Serial dilutions of known L. plantarum WCFS1 DNA, in amounts ranging from $1 \times 10^{4}$ to $1 \times 10^{8} \mathrm{CFU} / \mathrm{mL}$, were carried out to generate a reference standard curve, which was used for the relative quantification. 
The obtained human cDNA samples were also diluted (1:20), and $5 \mu \mathrm{L}$ were used to perform the Q-PCR analysis. Primers (100 nM of each primer) were selected from PrimerBank [55]. Primers related to glyceraldehyde phosphate dehydrogenase (GAPDH), $\beta$-actin ( $\beta$-actin), interleukin 8 (IL-8) and interleukin 6 (IL-6) genes were previously reported by Bove et al. [53]. Primers for the gene tumor necrosis factor $\alpha(\mathrm{TNF}-\alpha)$ were designed (Table 2). GAPDH, $\beta$-actin and hypoxanthine phosphoribosyl transferase 1 (HPRT1) genes were used to normalize the expression of target genes by the $2^{-\Delta \Delta \mathrm{Ct}}$ method [56].

The thermal conditions were $95{ }^{\circ} \mathrm{C}$ for $10 \mathrm{~min}$ followed by 40 cycles of $95{ }^{\circ} \mathrm{C}$ for $20 \mathrm{~s}, 58{ }^{\circ} \mathrm{C}$ for $30 \mathrm{~s}$ and $72{ }^{\circ} \mathrm{C}$ for $30 \mathrm{~s}$. Each PCR assay included duplicate reactions.

Table 2. Oligonucleotides used in Q-PCR analysis.

\begin{tabular}{|c|c|c|}
\hline Oligonucleotide & Name & Sequence $\left(5^{\prime}-3^{\prime}\right)$ \\
\hline 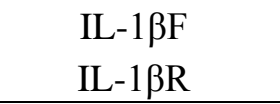 & Interleukin $1 \beta$ & $\begin{array}{c}\text { ATGATGGCTTATTACAGTGGCAA } \\
\text { GTCGGAGATTCGTAGCTGGA }\end{array}$ \\
\hline 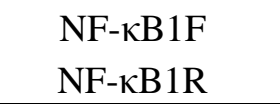 & Nuclear factor kappa B & $\begin{array}{l}\text { GGTGCGGCTCATGTTTACAG } \\
\text { GATGGCGTCTGATACCACGG }\end{array}$ \\
\hline $\begin{array}{l}\text { IL-10F } \\
\text { IL-10R }\end{array}$ & Interleukin 10 & $\begin{array}{c}\text { GACTTTAAGGGTTACCTGGGTTG } \\
\text { TCACATGCGCCTTGATGTCTG }\end{array}$ \\
\hline $\begin{array}{l}\text { TSLPF } \\
\text { TSLPR }\end{array}$ & Thymic stromal lymphopoietin & $\begin{array}{c}\text { ATGTTCGCCATGAAAACTAAGGC } \\
\text { GCGACGCCACAATCCTTGTA }\end{array}$ \\
\hline $\begin{array}{l}\text { GAPDHF } \\
\text { GAPDHR }\end{array}$ & Glyceraldehyde phosphate dehydrogenase & $\begin{array}{l}\text { CGACCACTTTGTCAAGCTCA } \\
\text { AGGGGTCTACATGGCAACTG }\end{array}$ \\
\hline $\begin{array}{l}\beta \text {-actF } \\
\beta \text {-actR }\end{array}$ & $\beta$-Actin & $\begin{array}{l}\text { AAAGACCTGTACGCCAACAC } \\
\text { CATACTCCTGCTTGCTGATCC }\end{array}$ \\
\hline $\begin{array}{l}\text { IL-6F } \\
\text { IL-6R }\end{array}$ & Interleukin 6 & $\begin{array}{l}\text { TACCCCCAGGAGAAGATTCC } \\
\text { TTTTCTGCCAGTGCCTCTTT }\end{array}$ \\
\hline $\begin{array}{l}\text { IL-8F } \\
\text { IL-8R }\end{array}$ & Interleukin 8 & $\begin{array}{l}\text { TGTGGAGAAGTTTTTGAAGAGGG } \\
\text { CCAGGAATCTTGTATTGCATCTGG }\end{array}$ \\
\hline $\begin{array}{l}\text { TNF- } \alpha \mathrm{F} \\
\text { TNF- } \alpha \mathrm{R}\end{array}$ & Tumor necrosis factor $\alpha$ & $\begin{array}{l}\text { AACCTCCTCTCTGCCATCAA } \\
\text { ATGTTCGTCCTCCTCACAGG }\end{array}$ \\
\hline
\end{tabular}

\subsection{Statistical Analysis}

Each datum represents the mean \pm SD of two biological experiments and three technical replicates. Data were analyzed via principal components analysis (PCA) and the Student's $t$-test using the PAST version 2.17C software program [57]. $p<0.05$ and $p<0.005$ were considered as statistically significant.

\section{Conclusions}

We used two L. plantarum strains to produce yogurt in order to analyze their technological and probiotic features, focusing on the potential immunomodulatory ability. The yogurts obtained were shown to have: (i) a chemical profile similar to that of the control yogurt in terms of lactic acid, nitrogen fractions and fat content; (ii) a different profile of peptide content; and (iii) good stability over 28 days of storage. Moreover, the viability of inoculated strains was persistent over the shelf-life, and all L. plantarum strains inoculated into the yogurt matrix were able to tolerate the oral, gastric and intestinal 
stress conditions. The strain, L. plantarum CECT 8328, performed better compared to L. plantarum WCFS1. Finally, the transcriptional analysis of genes involved in the immune response showed that the studied probiotic bacteria possibly have a positive influence on immunomodulation, and this feature is not affected during the human digestion process. In summary, the tested Lactobacilli exhibited suitable technological features for yogurt production, and we suggest that they might be used as immunomodulating strains to formulate novel foods with beneficial effects on immune homeostasis.

\section{Acknowledgments}

This work was partially supported by MIUR (Ministero dell'Istruzione, dell'Universtà e della Ricerca) (PON02_00186_2937475) in the framework of the project named "Protocolli innovativi per lo sviluppo di alimenti funzionali” (Pro.Ali.Fun.).

\section{Author Contributions}

Mattia P. Arena and Graziano Caggianiello carried out the experiments. Marzia Albenzio carried out the chemical analysis of milk and yogurt. Pasquale Russo and Vittorio Capozzi analyzed the experimental data and contributed to critical reading of the paper. Giuseppe Spano, Salvatore Massa and Daniela Fiocco participated in the design of the experimental plans, coordination and critical reading of the paper. All authors read and approved the final manuscript.

\section{Conflicts of Interest}

The authors declare no conflict of interest.

\section{References}

1. Prado, F.C.; Parada, J.L.; Pandey, A.; Soccol, C.R. Trends in non-dairy probiotic beverages. Food Res. Int. 2008, 41, 111-123.

2. Gorbach, S.L. Probiotics in the third millennium. Dig. Liver Dis. 2002, 34, S2-S7.

3. Guidelines for the Evaluation of Probiotics in Food. Food and Agriculture Organization of United Nations and World Health Organization Working Group Report, 2002. Available online: ftp://ftp.fao.org/es/esn/food/wgreport2.pdf (accessed on 14 May 2014).

4. Vinderola, G.; Matar, C.; Perdigon, G. Role of intestinal epithelial cells in immune effects mediated by gram-positive probiotic bacteria: Involvement of toll-like receptors. Clin. Diagn. Lab. Immunol. 2005, 12, 1075-1084.

5. Holzapfel, W.H.; Haberer, P.; Snel, J.; Schillinger, U.; Huis in’t Veld, J.H.J. Overview of gut flora and probiotics. Int. J. Food Microbial. 1998, 41, 85-101.

6. Marteau, P.R.; de Vrese, M.; Cellier, C.J.; Schrezenmeir, J. Protection from gastrointestinal diseases with the use of probiotics. Am. J. Clin. Nutr. 2001, 73, 430s-436s.

7. Patel, R.M.; Lin, P.W. Developmental biology of gut-probiotic interaction. Gut Microbes 2010, 1, 186-195. 
8. Ulluwishewa, D.; Anderson, R.C.; McNabb, W.C.; Moughan, P.J.; Wells, J.M.; Roy, N.C. Regulation of tight junction permeability by intestinal bacteria and dietary components. $J$. Nutr. 2011, 141, 769-776.

9. Coico, R.; Sunshine, G.; Benjamini, E. Immunology: A Short Course; Wiley-Liss: New York, NY, USA, 2003.

10. Jung, H.C.; Eckmann, L.; Yang, S.-K.; Panja, A.; Fierer, J.; Morzycka-Wroblewska, E.; Kagnoff, M.F. A distinct array of proinflammatory cytokines is expressed in human colon epithelial cells in response to bacterial invasion. J. Clin. Investig. 1995, 95, 55-65.

11. Delcenserie, V.; Martel, D.; Lamoureux, M.; Amiot, J.; Boutin, Y.; Roy, D. Immunomodulatory effects of probiotics in the intestinal tract. Curr. Issues Mol. Biol. 2008, 10, 37-54.

12. Maccaferri, S.; Klinder, A.; Brigidi, P.; Cavina, P.; Costabile, A. Potential probiotic Kluyveromyces marxianus B0399 modulates the immune response in Caco-2 cells and peripheral blood mononuclear cells and impacts the human gut microbiota in an in vitro colonic model system. Appl. Environ. Microbial. 2012, 78, 956-964.

13. Hart, A.; Kamm, M.A. Mechanisms of initiation and perpetuation of gut inflammation by stress. Aliment. Pharmacol. Ther. 2002, 16, 2017-2028.

14. Thomas, D.J.; Husmann, R.J.; Villamar, M.; Winship, T.R.; Buck, R.H.; Zuckermann, F.A. Lactobacillus rhamnosus HN001 attenuates allergy development in a pig model. PLoS One 2011, 6, e16577, doi:10.1371/journal.pone.0016577.

15. Mullin, J.M.; Valenzano, M.C.; Verrecchio, J.J.; Kothari, R. Age-and diet-related increase in transepithelial colon permeability of Fischer 344 rats. Dig. Dis. Sci. 2002, 47, 2262-2270.

16. Wichers, H. Immunomodulation by food: Promising concept for mitigating allergic disease? Anal. Bioanal. Chem. 2009, 395, 37-45.

17. Haller, D.; Bode, C.; Hammes, W.P.; Pfeifer, A.M.; Schiffrin, E.J.; Blum, S. Non-pathogenic bacteria elicit a differential cytokine response by intestinal epithelial cell/leucocyte co-cultures. Gut 2000, 47, 79-87.

18. Ranadheera, C.S.; Evans, C.A.; Adams, M.C.; Baines, S.K. Effect of dairy probiotic combinations on in vitro gastrointestinal tolerance, intestinal epithelial cell adhesion and cytokine secretion. J. Funct. Foods 2014, 8, 18-25.

19. Grimoud, J.; Durand, H.; de Souza, S.; Monsan, P.; Ouarné, F.; Theodorou, V.; Roques, C. In vitro screening of probiotics and synbiotics according to anti-inflammatory and anti-proliferative effects. Int. J. Food Microbial. 2010, 144, 42-50.

20. Pelto, L.; Isolauri, E.; Lilius, E.M.; Nuutila, J.; Salminen, S. Probiotic bacteria down-regulate the milk-induced inflammatory response in milk hypersensitive subjects but have an immunostimulatory effect in healthy subjects. Clin. Exp. Allergy 1998, 28, 1474-1479.

21. Ogawa, T.; Asai, Y.; Tamai, R.; Makimura, Y.; Sakamoto, H.; Hashikawa, S.; Yasuda, K. Natural killer cell activities of synbiotic Lactobacillus casei ssp. casei in conjunction with dextran. Clin. Exp. Immunol. 2006, 143, 103-109.

22. Chandan, R.C.; Kilara, A. Manufacturing Yogurt and Fermented Milks, 2nd ed.; Wiley-Blackwell: Hoboken, NJ, USA, 2013.

23. Mollet, B. Genetically improved starter strains: Opportunities for the dairy industry. Int. Dairy J. 1999, 9, 11-15. 
24. Papadimitriou, C.G.; Vafopoulou-Mastrojiannaki, A.; Silva, S.V.; Gomes, A.M.; Malcata, F.X.; Alichanidis, E. Identification of peptides in traditional and probiotic sheep milk yoghurt with angiotensin I-converting enzyme (ACE)-inhibitory activity. Food Chem. 2007, 105, 647-656.

25. Bautista, E.S.; Dahiya, R.S.; Speck, M.L. Identification of compounds causing symbiotic growth of Streptococcus thermophilus and Lactobacillus bulgaricus in milk. J. Dairy Res. 1966, 33, 299-307.

26. Rajagopal, S.N.; Sandine, W.E. Associative growth and proteolysis of Streptococcus thermophilus and Lactobacillus bulgaricus in skim milk. J. Dairy Sci. 1990, 73, 894-899.

27. Àlvarez, G.; González, M.; Isabal, S.; Blanc, V.; León, R. Method to quantify live and dead cells in multi-species oral biofilm by real-time PCR with propidium monoazide. AMB Express 2013, 3, 1, doi:10.1186/2191-0855-3-1.

28. Shortt, C. The probiotics century: Historical and current perspectives. Trends Food Sci. Technol. 1999, 10, 411-417.

29. Arena, M.P.; Russo, P.; Capozzi, V.; López, P.; Fiocco, D.; Spano, G. Probiotic abilities of riboflavin-overproducing Lactobacillus strains: A novel promising application of probiotics. Appl. Microbiol. Biotechnol. 2014, 98, 7569-7581.

30. Arena, M.P.; Caggianiello, G.; Fiocco, D.; Russo, P.; Torelli, M.; Spano, G.; Capozzi, V. Barley $\beta$-glucans-containing food enhances probiotic performances of beneficial bacteria. Int. J. Mol. Sci. 2014, 15, 3025-3039.

31. Bove, P.; Russo, P.; Capozzi, V.; Gallone, A.; Spano, G.; Fiocco, D. Lactobacillus plantarum passage through an oro-gastro-intestinal tract simulator: Carrier matrix effect and transcriptional analysis of genes associated to stress and probiosis. Microbiol. Res. 2013, 168, 351-359.

32. Ranadheera, C.S.; Evans, C.A.; Adams, M.C.; Baines, S.K. In vitro analysis of gastrointestinal tolerance and intestinal cell adhesion of probiotics in goat's milk ice cream and yogurt. Food Res. Int. 2012, 49, 619-625.

33. Danis, V.A.; Franic, G.M.; Rathjen, D.A.; Brooks, P.M. Effects of granulocyte-macrophage colony-stimulating factor (GM-CSF), IL-2, interferon-gamma (IFN- $\gamma$ ), tumour necrosis factor-alpha (TNF-alpha) and IL-8 the production of immunoreactive IL-1 and TNF-alpha by human monocytes. Clin. Exp. Immunol. 1991, 85, 143-150.

34. Roebuck, K.A. Regulation of interleukin-8 gene expression. J. Interf. Cytokine Res. 1999, 19, 429-438.

35. DeNichilo, M.O.; Stewart, A.G.; Vadas, M.A.; Lopez, A.F. Granulocyte-macrophage colonystimulating factor is a stimulant of platelet-activating factor and superoxide anion generation by human neutrophils. J. Biol. Chem. 1991, 266, 4896-4902.

36. Ferrante, A. Activation of neutrophils by interleukins-1 and -2 and tumor necrosis factors. Immunol. Ser. 1992, 57, 417-436.

37. Sims, J.E.; Smith, D.E. The IL-1 family: Regulations of immunity. Immunology 2010, 10, 89-102.

38. Riedel, C.U.; Foata, F.; Philippe, D.; Adolfsson, O.; Eikmanns, B.J.; Blum, S. Anti-inflammatory effects of bifidobacteria by inhibition of LPS-induced NF-kappaB activation. World J. Gastroenterol. 2006, 12, 3729-3735.

39. Erickson, K.L.; Hubbard, N.E. Probiotic immunomodulation in health and disease. J. Nutr. 2000, 130, 403S-409S. 
40. Candela, M.; Perna, F.; Carnevali, P.; Vitali, B.; Ciati, R.; Gionchetti, P.; Rizzello, F.; Campieri, M.; Brigidi, P. Interaction of probiotic Lactobacillus and Bifidobacterium strains with human intestinal epithelial cells: Adhesion properties, competition against enteropathogens and modulation of IL-8 production. Int. J. Food Microbial. 2008, 125, 286-292.

41. Cui, H.H.; Chen, C.L.; Wang, J.D.; Yang, Y.J.; Cun, Y.; Wu, J.B.; Liu, Y.H.; Dan, H.L.; Jian, Y.T.; Chen, X.Q. Effects of probiotic on intestinal mucosa of patients with ulcerative colitis. World J. Gastroenterol. 2004, 10, 1521-1525.

42. Taylor, B.C.; Zaph, C.; Troy, A.E.; Du, Y.; Guild, K.J.; Comeau, M.R.; Artis, D. TSLP regulates intestinal immunity and inflammation in mouse models of helminth infection and colitis. $J$. Exp. Med. 2009, 206, 655-667.

43. Li, M.; Zhang, J.; Wu, Y.; Li, J. The regulation of thymic stromal lymphopoietin in gut immune homeostasis. Dig. Dis. Sci. 2011, 56, 2215-2220.

44. Comeau, M.R.; Ziegler, S.F. The influence of TSLP on the allergic response. Mucosal Immunol. 2010, 3, 138-147.

45. Takai, T. TSLP expression: Cellular sources, triggers, and regulatory mechanisms. Allergol. Int. 2012, 61, 3-17.

46. Kleerebezem, M.; Boekhorst, J.; van Kranenburg, R.; Molenaar, D.; Kuipers, O.P.; Leer, R.; Tarchini, R.; Peters, S.A.; Sandbrink, H.M.; Fiers, M.W.; et al. Complete genome sequence of Lactobacillus plantarum WCFS1. Proc. Natl. Acad. Sci. USA 2003, 100, 1990-1995.

47. Rosburg, V.; Boylston, T.; White, P. Viability of Bifidobacteria strains in yogurt with added oat beta-glucan and corn starch during cold storage. J. Food Sci. 2010, 75, C439-C444.

48. Association of Official Analytical Chemists (AOAC). Official Methods of Analysis, 16th ed.; Association of Official Analytical Chemists: Arlington, VA, USA, 1995.

49. British Standards Institution. Determination of Fat Content of Milk and Milk Products (Gerber Method); British Standards Institution: London, UK, 1989.

50. Kuchroo, C.N.; Fox, P.F. Soluble nitrogen in Cheddar cheese: Comparison of extraction procedures. Milchwissenschaft 1982, 37, 331-335.

51. Vreeburg, R.A.; Bastiaan-Net, S.; Mes, J.J. Normalization genes for quantitative RT-PCR in differentiated Caco-2 cells used for food exposure studies. Food Funct. 2011, 2, 124-129.

52. Quigley, L.; O’Sullivan, O.; Beresford, T.P.; Paul Ross, R.; Fitzgerald, G.F.; Cotter, P.D. A comparison of methods used to extract bacterial DNA from raw milk and raw milk cheese. J. Appl. Microbiol. 2012, 113, 96-105.

53. Bove, P.; Gallone, A.; Russo, P.; Capozzi, V.; Albenzio, M.; Spano, G.; Fiocco, D. Probiotic features of Lactobacillus plantarum mutant strains. Appl. Microbiol. Biotechnol. 2012, 96, 431-441.

54. Fiocco, D.; Collins, M.; Muscariello, L.; Hols, P.; Kleerebezem, M.; Msadek, T.; Spano, G. The Lactobacillus plantarum ftsH gene is a novel member of the CtsR stress response regulon. J. Bacteriol. 2009, 191, 1688-1694.

55. Spandidos, A.; Wang, X.; Wang, H.; Seed, B. PrimerBank: A resource of human and mouse PCR primer pairs for gene expression detection and quantification. Nucl. Acids Res. Database Issue 2010, 38, 792-799.

56. Livak, K.J.; Schmittgen, T.D. Analysis of relative gene expression data using real-time quantitative PCR and the $2^{-\Delta \Delta \mathrm{Ct}}$ Method. Methods 2001, 25, 402-408. 
57. Hammer, Ø.; Harper, D.A.T.; Ryan, P.D. Past: Paleontological statistics software package for education and data analysis. Paleontología Electrónica 2001, 4, 1-9.

(C) 2015 by the authors; licensee MDPI, Basel, Switzerland. This article is an open access article distributed under the terms and conditions of the Creative Commons Attribution license (http://creativecommons.org/licenses/by/4.0/). 